\title{
Effect of Apricot Fruit and Kernel Extracts on in-vitro Dissolution of Cholesterol Gallstones: Implication for Development of Potent Anti-cholilithiaticc agent
}

\author{
Sunita Waila Tiwari, Archana Negi Sah* \\ Department of Pharmaceutical Sciences, Faculty of Technology, Bhimtal Campus, Kumaun University Nainital, Uttarakhand, INDIA.
}

\begin{abstract}
Prunus armeniaca L. (apricot) belonging to family Rosaceae is an important edible medicinal plant containing many important constituents like polysaccharides, polyphenol, fatty acid and carotenoids. In this study, we attempted to assess the in-vitro anti-gall bladder stones activity (anticholilithiatic activity) of Prunus armeniaca L. (apricot) kernel and fruit extracts. Methodology: For this study, some human gall bladder stones (cholesterol and pigment stones) along with human bile, were collected from hospitals, incubated in human bile and treated with a combination of apricot fruit and kernel extracts in two doses $(1 \mathrm{mg} / \mathrm{ml}$ and $2 \mathrm{mg} / \mathrm{ml}$ ) and standard drug (ursodiol, $2 \mathrm{mg} / \mathrm{ml}$ ) for 4 weeks. Dried weight of gallstones and the amount of cholesterol released, before and after treatment were calculated. Results: From this experiment, it was found that the dried weight of cholesterol gallstones was reduced and the amount of cholesterol released from gallstones was increased in a dose-dependent manner, due to the effect of extracts. Morphological changes like color and fragility in gall stones were also observed due to the effect of extracts. Conclusion: This in-vitro study has given the primary evidence that the combination of apricot kernel and fruit extracts may cause the complete dissolution of cholesterol gallstones thus have the anti-cholilithiatic activity. Further in-vivo studies can be carried out on these extracts of apricot.
\end{abstract}

Key words: Cholelithiasis, Gallstones, Kernel, Ursodiol, Prunus armeniaca L.

\section{INTRODUCTION}

According to Ayurvedic, Chinese, European and other systems of traditional medicines natural remedies are used for the treatment of various diseases. ${ }^{1,2}$ Many countries are producers of medicinal plants which play an important role in the health and wellbeing of humans and animals. India is one of them. According to WHO, $80 \%$ of the world's population is currently using traditional medicines and herbs to cure various diseases, due to their fewer side effects and low cost. ${ }^{3}$ Prunus armeniaca L. (apricot) is a fruit tree belonging to family Rosaceae and is mostly cultivated in Korea, China, India, Japan, Iran, North Africa and the United States of America. ${ }^{4,5}$ Wild Apricot (Prunus armeniaca L.) commonly known as 'khubani' is a potential fruit widely distributed in North-West Himalayan regions of India. In India, it is also grown in Almora, Pithoragarh and Nainital district of Uttarakhand. The apricot fruit is a very good source of carbohydrates, vitamins and minerals, having an attractive color and characteristic flavor. Apricot and its kernel have many pharmacological actions like anti-aging, anti-atherosclerosis, anti-anginal and antioxidant activity. It is also used as a cardiac, hepatic and renoprotective agent. It contains various minerals (especially $\mathrm{K}, \mathrm{Fe}$, $\mathrm{Mg}, \mathrm{P}$ and $\mathrm{Se}$ ) and vitamins (A, C and $\mathrm{E})$. Apricot is a rich source of fiber and also has antispasmodic, antitussive, sedative and anti-inflammatory activities. ${ }^{6-14}$ Gall stone formation which is also called cholelithiasis, is a highly prevalent gastrointestinal disorder
Submission Date: 28-01-2020; Revision Date: 21-04-2020; Accepted Date: 19-05-2020

DOI: 10.5530/ijper.54.3.127 Correspondence: Dr. Archana Negi Sah Department of Pharmaceutical sciences, Bhimtal Campus, Bhimtal, Kumaun University, Nainital-263136, Uttarakhand, INDIA.

Phone: +919410566599 E-mail: drarchanansah@ gmail.com

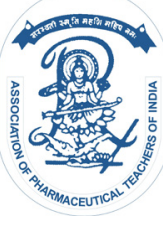

www.ijper.org 
that occurs due to disturbance in biliary homeostasis and hepatic cholesterol levels. ${ }^{15}$ Gallstone is a major health problem, found in about $15 \%$ of the population in most developing countries. There are 8 types of gallstones most common are of two types; $80 \%$ are composed of cholesterol called cholesterol gallstones, while $20 \%$ are made up of calcium and bilirubin known as pigment stones. ${ }^{16}$ Oral bile salt therapy may dissolve such gallstones, but was largely abandoned because of low efficacy. Cholecystectomy (removal of the gallbladder) is currently the only practical option for patients with symptomatic or complicated gallstone disease. Traditionally it was found that, in European folk medicine, consumption of apricot and their seed cores are used to cure microlithiasis and biliary lithiasis. They also have a choleretics effect (help to evacuate bile into the cholecyst) and may dissolve the biliary calculi. ${ }^{17}$ Thus, on a traditional basis, this study was designed to validate the effects of apricot fruit and kernel extracts in gallstone disease by using an in-vitro anti-cholilithiatic model.

\section{MATERIALS AND METHODS}

Collection and authentication of plant material: For this study, the fresh apricot fruits were collected in April from the villages Dugtanidhar and Satbuna (Mukteshwar), district Nainital, Uttarakhand, India. The sample was authenticated (voucher specimen no. 118202) by the BSI (Botanical Survey of India), Dehradun, Uttarakhand.

\section{Research design}

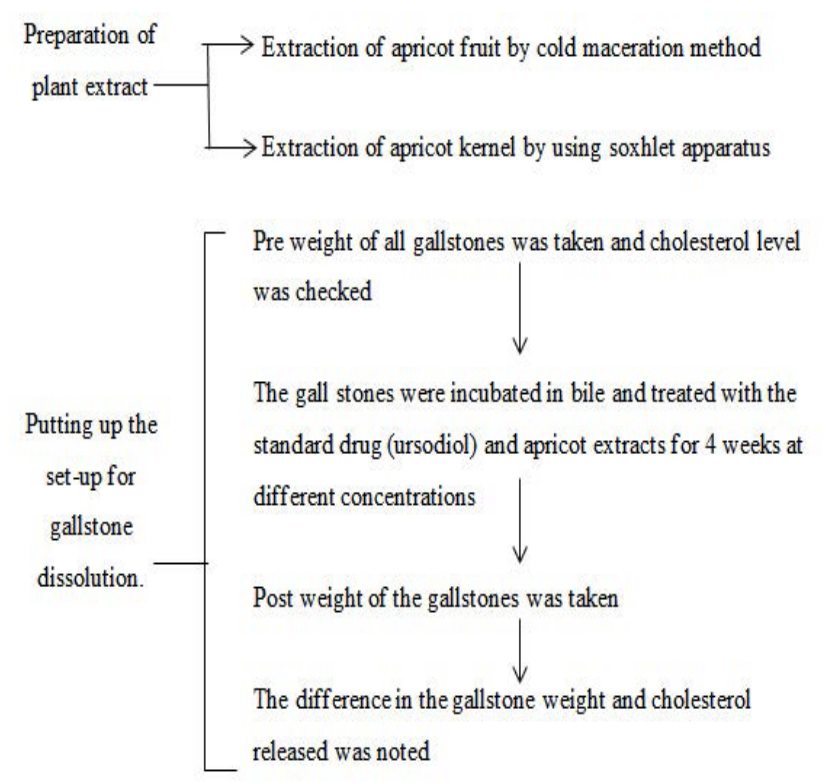

\section{Preparation of plant extracts}

Apricot fruit extract was prepared by using the cold maceration method (Figure 1). For this, the collected fresh apricot fruits were shade-dried. After that, the dried pulp of fruits was soaked in ethanol at room temperature for one week and then filtered. The prepared extract was then concentrated by vacuum evaporation and stored in a capped bottle at 4 degrees centigrade in a refrigerator for further use (yield $30.04 \% \mathrm{w} / \mathrm{w}$ ).

For the preparation of kernel extract, kernels were isolated from fresh apricot fruits and shade dried. After that, dried kernels were grounded to a coarse powder. This powdered sample was extracted in petroleum ether by using soxhlet apparatus for 6-8 $\mathrm{hr}$ at 70 degrees centigrade (Figure 2). The extract was then filtered through the Buckner funnel. Then it was filtered through Whatman filter paper and concentrated with a rotary evaporator at a temperature up to 40 degrees centigrade (yield 28.81\% w/w).

\section{Drugs and chemicals}

Normal saline $(0.9 \%)$, ethanol, $10 \%$ formalin, distilled water and standard drug (ursodiol) were used in this study.

\section{Equipments and kits}

Soxhlet apparatus, rotatory evaporator, auto analyzer, stopwatch, water bath and commercially available kits (AUTOSPANR Liquid Gold Cholesterol) to measure lipid profile were used in the study.

\section{In-vitro model of cholelithiasis}

For in-vitro activity, some gallstones (cholesterol and pigment stones) along with human bile were collected from different hospitals (Amrit Hospital, Rudrapur and Brijlal Hospital, Haldwani, Uttarakhand, India). All gall bladder stones were dried at 45 degrees centigrade in an oven and their dry weight was taken in an airtight electronic balance. After that, all gallstones were incubated in human bile and treated with a combination of fruit and kernel extracts in different concentrations $(1 \mathrm{mg} / \mathrm{ml}$ and $2 \mathrm{mg} / \mathrm{ml}$ ) and standard drug (ursodiol, 2 $\mathrm{mg} / \mathrm{ml}$ ) separately for 4 weeks at 37 degrees centigrade. During incubation, the gallstones were picked up, dried and then their dry weights were taken weekly. The amount of cholesterol released from stones was also measured weekly by using the autoanalyzer. The differences in gall stone weight and amount of cholesterol released, before and after treatment were observed, to observe the effect of extracts and reference drug on gallstones. ${ }^{18}$ 


\section{RESULTS}

During this experiment, all gallstones were observed weekly to check the effect of apricot fruit and kernel extracts on the in-vitro dissolution of cholesterol gallstones \{Figure 3(a)-3(d)\}. When gallstones were incubated with standard drug ursodiol along with human bile, both the cholesterol gallstones (CS-1 and CS-2) were completely dissolved within 21 days of treatment. While no dissolution effect was found in pigment stones after the same treatment. During incubation with apricot kernel and fruit extracts, along with human bile, the negligible effect was observed on the dry weight of pigment stone (PS) because a very minute amount of weight reduced after treatment (Figure 5). However, the weight of cholesterol gallstones (CS-1 and CS-2) was decreased after treatment with extracts within 14 days and they were completely dissolved after 21 days of treatment (Figures 6 and 7). Morphological changes were also observed in stones after treating with plant extracts, like the color of cholesterol stones was changed from yellowish-brown to white. While no color changes were observed in pigment stones. The cholesterol stones were much harder before treatment and

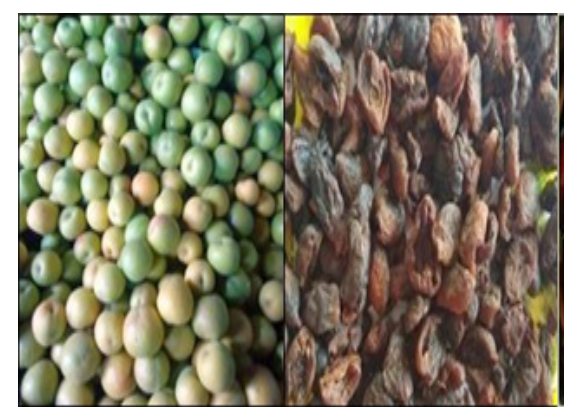

(A)

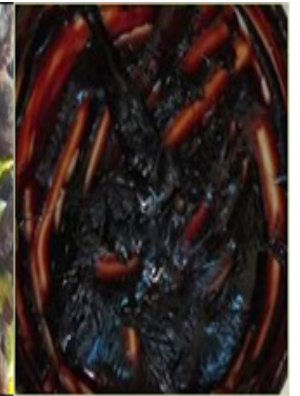

(C)
Figure 1: Illustration shows, extraction from apricot fruits by cold maceration method, where (A): Apricot fruit, (B): Dried apricot fruit (C): Apricot fruit extract.

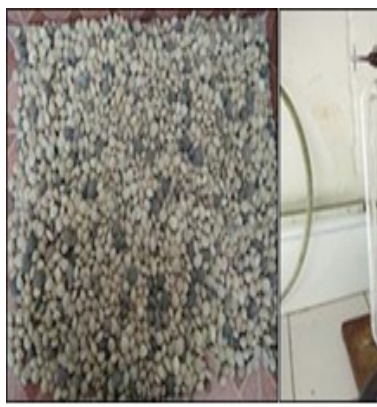

(A)

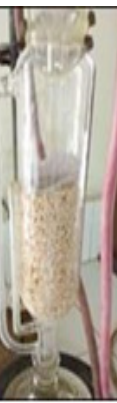

(B)

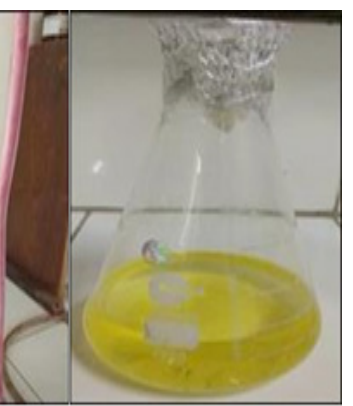

(C)
Figure 2: Illustration shows, extraction from the apricot kernel by using soxhlet apparatus, where (A): Apricot seeds (B): Apricot kernels in soxhlet apparatus (C): Apricot seed extract. fragility was observed after treating with extracts. The cholesterol content of the gallbladder stones before and after treatment with extracts and reference drugs were also estimated and it was observed that with the increase in the concentration of apricot fruit and kernel extracts, the amount of cholesterol released was also found to be increased. The highest amount of cholesterol (377.3 $\mathrm{mg} / \mathrm{dl}$ ) was released when gallstones were treated with apricot fruit and kernel extracts at a higher dose $(2 \mathrm{mg} /$ $\mathrm{ml}$ ) for 21 days. While the lowest amount was released $(291.41 \mathrm{mg} / \mathrm{dl})$ when gallstones were treated with apricot fruit and kernel extracts at a lower dose $(1 \mathrm{mg} /$ $\mathrm{ml}$ ) for 7 days (Figure 4).

\section{DISCUSSION}

Cholesterol gallstone disease is a major health problem caused by the imbalance between cholesterol and cholic acid. Gallstones might lead to cholecystitis, pancreatitis, biliary tract obstruction and gall bladder cancer. ${ }^{19}$ Prunus armeniaca L. is the plant, which is commonly used in Ayurveda as an anti-diarrhoeal, anti-pyretic, laxative, carminative and expectorant. ${ }^{20,21}$ The present study was carried out to assess the anticholelithiatic potential of

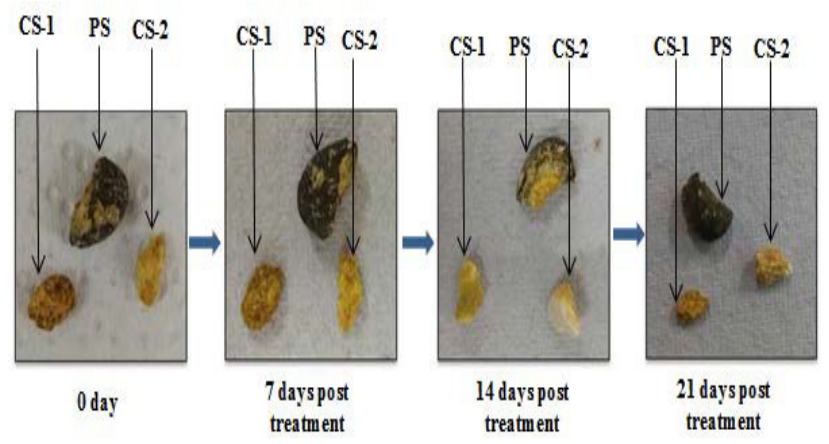

Figure 3a: Illustration shows, control group (C): In-vitro dissolution of gallstones [Cholesterol Stones (CS-1, CS-2) and Pigment stone (PS)] in human bile at different time intervals.

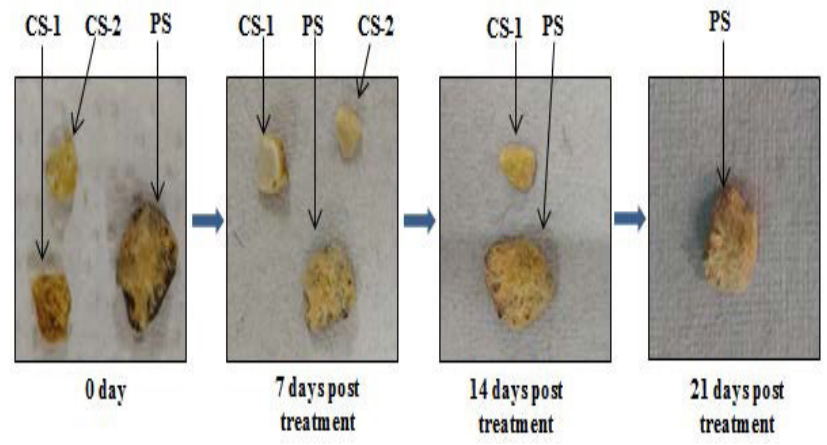

Figure 3b: Illustration shows, standard group (SD): In-vitro dissolution of gallstones [Cholesterol Stones (CS-1, CS-2) and Pigment stone (PS)] in human bile after treating with standard drug ursodiol $(1 \mathrm{mg} / \mathrm{ml})$ at different time intervals. 

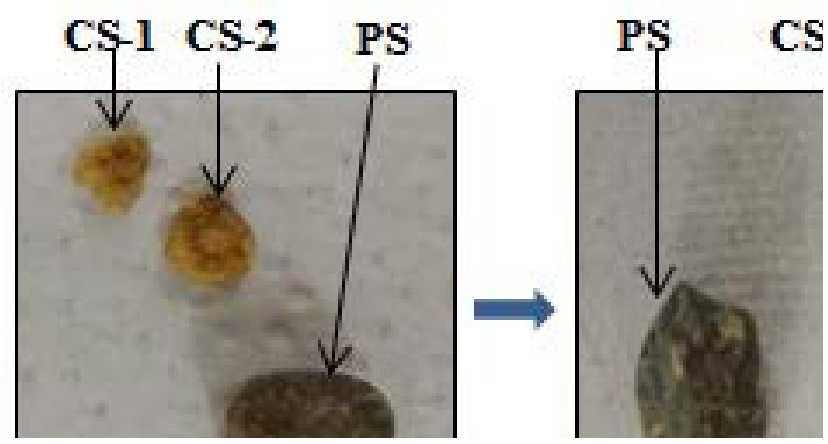

Figure 3c: Illustration shows, treatment group (T1): In-vitro dissolution of gallstones [Cholesterol Stones (CS-1, CS-2) and Pigment stone (PS)] in human bile after treating with apricot kernel and fruit extract in combination $(1 \mathrm{mg} / \mathrm{ml})$ at different time intervals.

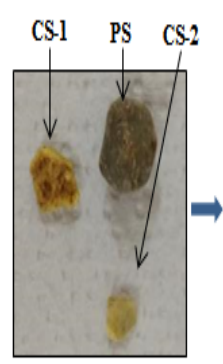

Oday

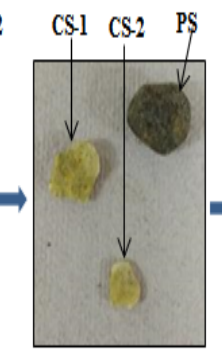

7 days post treatment

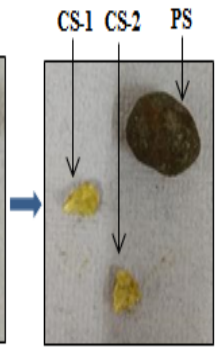

14 days post treatment

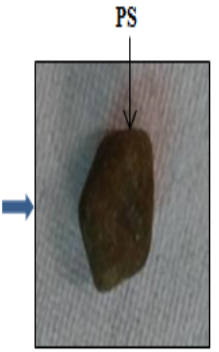

21 days post treatment
Figure 3d: Illustration shows, treatment group $\left(\mathrm{T}_{2}\right)$ : In-vitro dissolution of gallstones [Cholesterol Stones (CS-1, CS-2) and Pigment stone (PS)] in human bile after treating with apricot kernel and fruit extract in combination $(2 \mathrm{mg} / \mathrm{ml})$ at different time intervals.

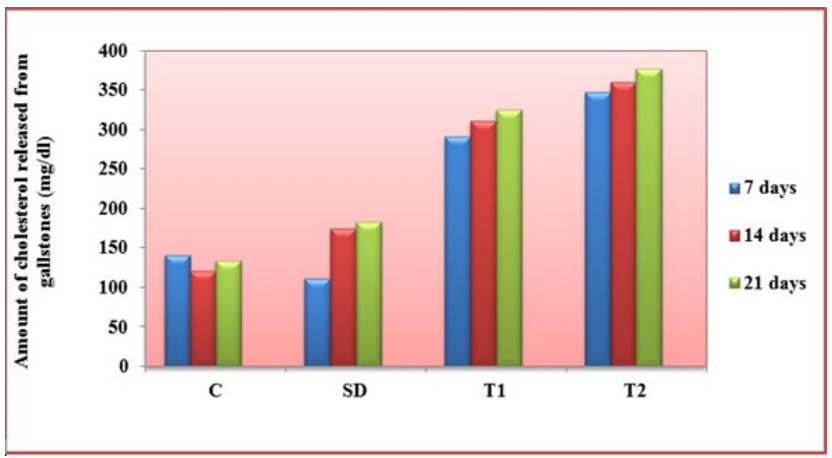

Figure 4: Bargraph shows, amount of cholesterol released from gallbladder stones at different time intervals: $\mathbf{C}$ (control group), SD (ursodiol $1 \mathrm{mg} / \mathrm{ml}$ ), $\mathrm{T}_{1}$ (Apricot extracts, $1 \mathrm{mg} / \mathrm{ml}$ ), $\mathrm{T}_{2}$ (Apricot extracts, $2 \mathrm{mg} / \mathrm{ml}$ ).

P. armeniaca $\mathrm{L}$. by in vitro study. In this study, human gallstones along with bile were taken and treated with apricot kernel and fruit extract for 4 weeks. During this study, it was observed that cholesterol gallstones got completely dissolved by both the apricot extracts. The presence of saponins may be responsible for its

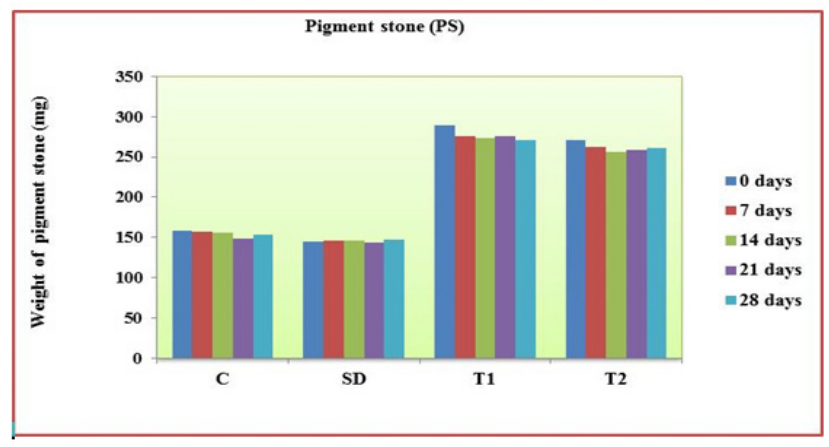

Figure 5: Bargraph shows, weight reduction of pigment stone at different time intervals: $C$ (control group), SD (ursodiol 1 $\mathrm{mg} / \mathrm{ml}$ ), $\mathrm{T}_{1}$ (Apricot extracts, $1 \mathrm{mg} / \mathrm{ml}$ ), $\mathrm{T}_{2}$ (Apricot extracts, 2 $\mathrm{mg} / \mathrm{ml}$ ).

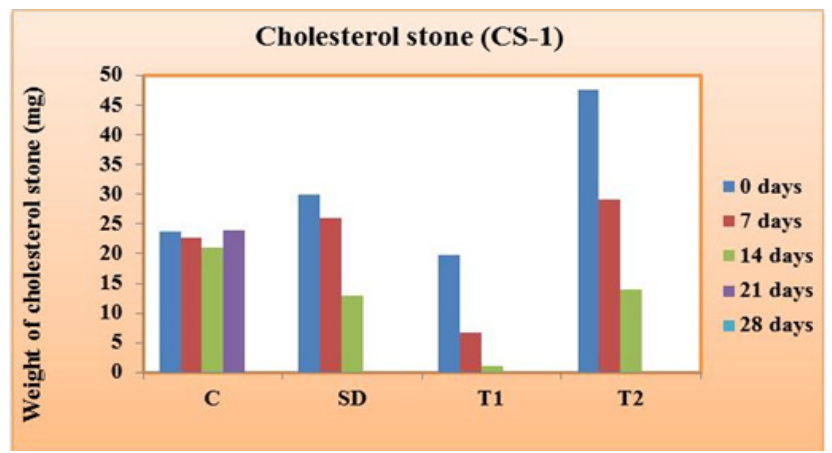

Figure 6: Bargraph shows, weight reduction of cholesterol gallstone (CS-1) at different time intervals: $\mathrm{C}$ (control group), SD (ursodiol, $1 \mathrm{mg} / \mathrm{ml}$ ), $\mathrm{T}_{1}$ (Apricot extracts, $1 \mathrm{mg} / \mathrm{ml}$ ), $\mathrm{T}_{2}$ (Apricot extracts, $2 \mathrm{mg} / \mathrm{ml})$.

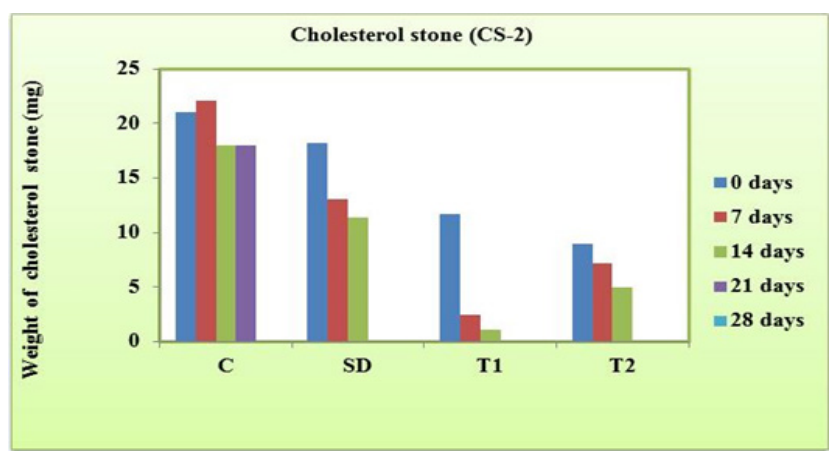

Figure 7: Column chart shows, weight reduction of cholesterol gallstone (CS-2) at different time intervals: $\mathbf{C}$ (control group), SD (ursodiol, $1 \mathrm{mg} / \mathrm{ml}$ ), $\mathrm{T}_{1}$ (Apricot extracts, $1 \mathrm{mg} / \mathrm{ml}$ ), $\mathrm{T}_{2}$ (Apricot extracts, $2 \mathrm{mg} / \mathrm{ml}$ ).

cholesterol dissolving activity ${ }^{22,23}$ because apricot was reported to contain saponins. ${ }^{13}$ It was also found in previous research studies that some plants containing magnesium exhibit anticholilithiatic effect. ${ }^{24}$ Thus the presence of magnesium may be the reason behind 
the anticholilithiatic activity of apricot as it is rich in magnesium. ${ }^{13}$

\section{CONCLUSION}

This study showed an appreciable degree of anticholilithiatic activity by apricot against gall bladder stones. The in-vitro treatment of gall stones with the apricot plant was not previously attempted. No established study was available in this regard. In-vitro anti-cholilithiatic activity has been performed on the selected plant Prunus armeniaca L. where ursodiol was used as a standard drug. The work was performed by using human gallstones and bile. After treatment with different doses of extracts, the amount of cholesterol released from stones was calculated and the weight of dried stones was noted. A combination of apricot kernel and fruit extract showed the complete dissolution of cholesterol gallstones during 4 weeks of treatment. The effect of apricot extracts on gall stones provided new findings and opened a new window to think about the potentials of this plant. This protocol was a preliminary approach that needs further in-vivo studies to help peoples to utilize the natural medication from this plant.

\section{ACKNOWLEDGEMENT}

We are thankful to the Department of Pharmaceutical Sciences, Faculty of Technology, Kumaun University, Nainital for providing necessary facilities to conduct the experimental work.

\section{CONFLICT OF INTEREST}

The authors declare no conflicts of interest.

\section{ABBREVIATIONS}

WHO: World Health Organization; CS: Cholesterol Gallstones; PS: Pigment Stone; BSI: Botanical Survey of India.

\section{REFERENCES}

1. Mohmed STS, Madusudhana CC, Ramkanth S, Rajan VST, Mahesh KK, Ghauthaman K. Hepatoprotective Herbs: A Review. Int J Res Pharm. 2010;1(1):1-5.
2. Arya V, Gupta VK. Review on some cardioprotective plant from Ayurveda. Int J Res Ayurveda Pharm. 2011;2:80-3.

3. Pandey G. Medicinal plant against liver disease. Int Res $\mathrm{J}$ Pharm. 2011;2(2):10-3.

4. Jones SB, Luchsinger AE. Plant systematic. $2^{\text {nd }}$ ed. New York: Mc Graw Hill. 1979.

5. WHO Monographs on Selected Medicinal Plants. Geneva: World Health Organization. 2007;1.

6. Afdhal $\mathrm{NH}$. Epidemiology, risk factors and pathogenesis of gallstones, Inc: Gallbladder and Biliary Tract Diseases. New York: Marcel Dekker. 2000.

7. Miyazawa M, Utsunomiya H, Inada K, Yamada T, Okuno Y, Tanaka H, et al. Inhibition of Helicobacter pylori motility by (+)-Syringaresinol from unripe Japanese apricot. Biol Pharm Bull. 2006;29(1):172-3.

8. Yigit D, Yigit N, Mavi A. Antioxidant and antimicrobial activities of bitter and sweet apricot (Prunus armeniaca L.) kernels. Brazil J Med Biol Res. 2009;42(4):346-52.

9. Yılmaz I. Antioksidan içeren bazı gıdalar ve oksidatif stress. J Turgut Ozal Med Cen. 2010;17(2):143-53.

10. Yılmaz I. The Biological and Pharmacological Importance of Apricot. SOJ Pharm Sci. 2010;5(1):1-4.

11. Erdogan OI, Kartal M. Insights into research on phytochemistry and biological activities of Prunus armeniaca L. (apricot). Food Res Inter. 2011;44(5):123843.

12. Raj V, Jain A, Chaudhary J. Prunus armeniaca (Apricot): An overview. J Pharm Res. 2012;5(8):3964-6.

13. Sharma S, Satpathy G, Gupta RK. Nutritional, phytochemical, antioxidant and antimicrobial activity of Prunus armeniaca. J Pharmacog Phytochem. 2014;3(3):23-8

14. Minaiyan M, Ghannadi A, Asadi M, Etemad M, Mahzouni P. Anti-inflammatory effect of Prunus armeniaca L. (Apricot) extracts ameliorates TNBS-induced ulcerative colitis in rats. Res Pharm Sci. 2014;9(4):225-31.

15. Marzolo MP, Rigotti A, Nervi F. Secretion of biliary lipids from the hepatocyte. Hepatology. 1990;12(3 Pt 2):134-42.

16. Jabeen $Q$, Jamshed A, Zulfiqar M, Rasheed HMF. Pharmacological Evaluation of Coriander Seeds against High Fat Diet-Induced Cholelithiasis. Adv Res Gastroentero Hepatol. 2018;8:1-5.

17. Crenguța R. Apricots, the wonder fruit. 2014. Available from: http:// www.yogaesoteric.net/content.aspx/www.yogaesoteric.net/files/content. aspx?lang=EN\&item $=7636$

18. Hossain J, Laila K, Masudul A, Chowdhury AM, Arifuzzaman MD, et al. AntiBacterial and Anti-Oxidant Activity of Achyranthes, Aspera Leaf Extract and Its Effect on Gall Bladder Stones. J Med Plants. 2013;1(3):105-17.

19. Tepperman J, Caldwell FT, Tepperman HM. Induction of gallstones in mice by feeding a cholesterol-cholic acid-containing diet. Am J Physiol Renal Physiol. 1964;206(3):628-34.

20. Parmar C, Sharma AKC. A wild apricot from Himalayan cold desert region. Fruit Var J. 1992;46:35-6.

21. Chevallier A. The Encyclopedia of Medicinal Plants: A Practical Reference Guide to over 550 Key Herbs and Their Medicinal Uses. New York: DK Publishing. 1996.

22. Matsuura H. Saponins in Garlic as Modifiers of the Risk of Cardiovascular Disease. J Nutr. 2001;131(3):1000-5.

23. Dubois MAL, Wagner H. A review of the biological and pharmacological activities of saponins. Phytomedicine. 1996;2(4):363-86.

24. Bigoniya B, Bais S, Sirohi B. The effect of Macrotyloma uniflorum seed on bile lithogenicity against diet-induced cholelithiasis on mice. Anc Sci Life. 2014;33(4):242-51. 
PICTORIAL ABSTRACT

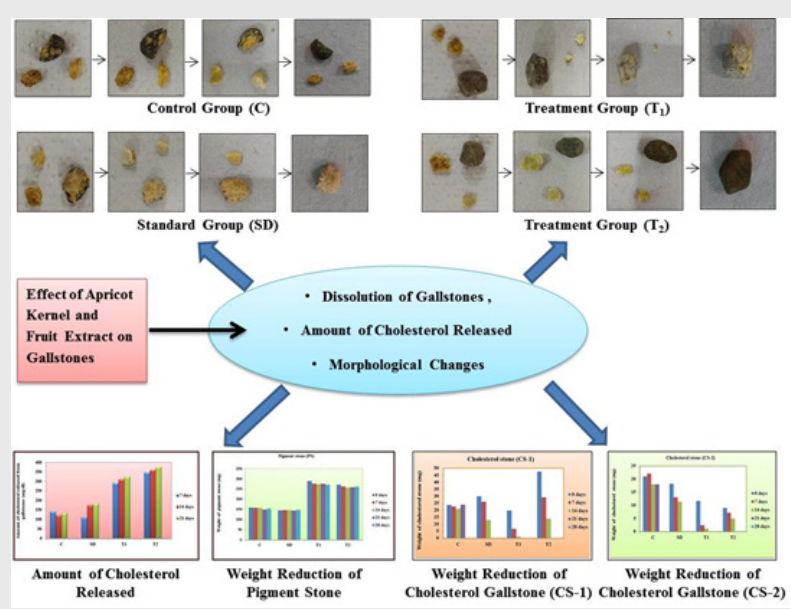

\section{SUMMARY}

The current study illustrated the anticholilithiatic activity of apricot kernel and fruit extract. A combination of apricot kernel and fruit extract showed the complete dissolution of cholesterol gallstones after incubation with human bile during 4 weeks of treatment. Extracts exhibited anti stone activity by increasing the release of cholesterol from stones and decreasing the weight of stones after treatment. While no dissolution effect and weight reduction was observed in pigment stones.

\section{About Authors}

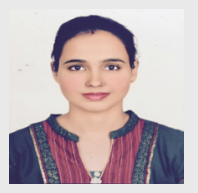

Sunita Waila Tiwari: She is a Doctoral student at the Department of Pharmaceutical Sciences, Faculty of Technology, Kumaun University, Bhimtal Campus Nainital, Uttarakhand, India. She is a recipient of the GPAT fellowship for the PG course. She has completed her Master of Pharmacy in Pharmacology. Her area of research is focused on the pharmacological activities of plant extracts.

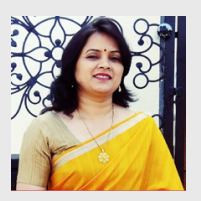

Dr. Archana Negi Sah: Is a Graduate in Pharmaceutical Sciences and Basic Sciences, Post Graduate in Herbal Drugs Technology and Ph.D. in Pharmacy. She is currently working as Head of Department in Department of Pharmaceutical Sciences, Faculty of Technology, Kumaun University, Bhimtal Campus, Nainital, Uttarakhand, India. Dr. Sah is a recipient of the UGC fellowship for the PG course and received first prize for paper presentation. She is supervising 4 Ph.D. Scholars and has supervised more than $20 \mathrm{M}$. Pharm. students in their research work. Dr. Sah is a member of different professional and academic bodies, published chapters, peer-reviewed national and international papers and delivered a range of presentations in different International and National Conferences.

Cite this article: Tiwari SW, Sah AN. Effect of Apricot Fruit and Kernel Extracts on in-vitro Dissolution of Cholesterol Gallstones: Implication for Development of Potent Anticholilithiatic agent. Indian J of Pharmaceutical Education and Research. 2020;54(3):755-60. 